\title{
Project Risk Management: Methodology Development for Engineering, Procurement and Construction Projects a Case Study in the Oil and Gas Industry
}

\author{
Ashwin Amarshi Maru \\ L.E.College, Civil engineering department, Saurashtra University, Rajkot, State: Gujarat, India
}

Email address:

maru.ashvin@gmail.com

To cite this article:

Ashwin Amarshi Maru. Project Risk Management: Methodology Development for Engineering, Procurement and Construction Projects a Case Study in the Oil and Gas Industry. American Journal of Civil Engineering. Vol. 3, No. 3, 2015, pp. 75-79. doi: 10.11648/j.ajce.20150303.14

\begin{abstract}
EPC Project comes with a set of risks that are unique and hence cannot be addressed in the context of general construction risks. This paper researches existing methodologies and presents a customizable framework for project risks assessment with EPC project. A case study specific to the Oil and Gas industry has been used. The developed framework is also extendable for other EPC works.
\end{abstract}

Keywords: Project Risk Management, Integrated Risk Management, Risks in Procurement, Risks in Construction, construction Management, Oil and Gas Industry, EPC (Engineering, Procurement, Construction)

\section{Introduction}

THE Construction Scientific management of risks is a growing need for construction projects. This is because of the rising amount of risks that are faced in the construction industry. Current risk management approaches need to be revised. This is primarily because most risk management approaches are applicable for different sections of the project development and there is a lack of an integrated approach in risk management [2]. The advantages and benefits of an integrated risk management from the procurement to the final engineering development would be helpful in handling concerns efficiently [3]. The basic aim of this project is to study about risks, risk management and to critically evaluate it for a case study. The case study is from the engineering, procurement and construction projects of the oil and gas industry.

Although various studies are available for information technology, manufacturing sectors, there has been no specific study for oil and gas industry [6]. This case study intends to benefit the oil and gas industry, and makes recommendations both general and specific that can be applied to meet the wholesome needs of the Oil and gas Industry. The Engineering procurement and Construction EPC background is the focus of research.

\section{Research Background}

A risk is defined as a deviation from a defined target. This deviation for a target with specifications is normally defined by uncertainty. It is unpredictable (although not always) and will have negative consequences on the defined target [9]. There is a great demand for Risk management solution providers, who systematically solve the issues and the problems to be, and also suggest a solution. Due to this calculated and scientific approach, the risks identified can be managed on a real time basis, without these problems affecting the whole project [5]. As such, this also holds benefits in the context of real time budgetary needs. Where risk management is achieved, it becomes easier to control the project costs, make the project work within the anticipated budget or to avail of fresh funds, and for easy prediction of the tentative project completion dates, as the Risk management solution involves all aspects of the project from Inventory, tender work, order finalization, human resources and the standards and quality aspects [8].

The purpose of this research is to analyze the overall parameters which are involved in uncertainties and can hence result in affectations to project completions during critical times. There are different methodologies towards risk management, a customized methodology that can be applied to Engineering, Procurement and Construction (EPC) projects 
in the oil and gas industry is discussed here. The case study project has been critically evaluated for risk management opportunities and strategies based on different methodologies.

\section{Literature Review}

There are many a concepts and studies with varying standards and methodologies to be applied in Risk Management, but none seems to be specific to address the issues of the Oil and Gas Industry. This project will ease that doubt and will try and cater to the issues pertaining to the Oil and gas Industry, and a systematic procedure will be developed to accurately evaluate any Oil and gas Projects.

The risk management study would identify the areas associated or prone for Risks right from the start and address those issues with a valid response or Decision making process [4]. As such valid decision making is essential in finalization of the contracts with the suppliers / vendors or in turnkey projects or any other joint venture or Build own operate processes. In any EPC Project, the Supplier of plant and machinery and his team is responsible for proper erection and execution of the plant and machinery. The key to identify the best realistic terms to be achieved rests with the identification of the inherent risks and the knowhow to solve the same.

Studies of Haghnevis and Sajedi present the gaps inherent in existing literature. Although there are several models, none of them address the EPC aspect comprehensively and every company's aspects on risk is much different from the other. Specificity often makes the research work inapplicable in a general context for the construction field [3]. EPC projects need a more focused framework.

Project risks in EPC will benefit by the application of the PMBOK (project management body of knowledge) standards. According to the standards, a project risk "is an uncertain event or condition that, if it occurs, has an effect on at least one project objective. A risk may have one or more causes and, if it occurs, it may have one or more impacts" [10]. These risks are either dynamic risks or static risks as can be classified according to their characteristics [9].

EPC contractual arrangement related risks can be of either type. EPC is a contractual arrangement in the construction industry where the contractor is made responsible for the engineering, designing and procurement details for construction [7]. There are cost based contracts and work based contracts and for the most part these risks are transferred to the [10].

Specific points of analyzing for the risks in these contracts are by planning, control and facilitating simultaneous activities and by use of risk management suites such as the IRM (Institute of risk management), PMBOK, PRMA (Public risk management association) and more.

\section{Methodology}

There are many a varied model of risk management theories, concepts, case studies available to suit many industries, but the one which can be related to be close to the Oil and gas industry would be the Construction industry and some of the common methodologies used for this industry are that of the Boehm, Fairley, SEI, Kliem \& Ludin, SHAMPU, PRAM, PMBOK, PRMA, Smith\& Merritt-all try to find solutions in Risk Management.

The most commonly used profile is that of PMBOK Model which is registered as an ANSI Standard. The PRINCE 2 Model is a solution provider is controlled Environments is widely used the Government Bodies in the United Kingdom, this software is available for free and due to which is used widely throughout the world.

Though these above cited methodologies provide solution in Risk Management, they were not developed to cater to any particular industry. They were developed as a Common application platform only, and not need based [5]. The Current project was assimilated by conducting various sessions of rigorous data Collection for Empirical work and for theoretical framework, data analysis, and associating those data with the selected Oil And Gas Company. The company for which information is collated and studied is the on-going Iranian EPC oil and gas project called "Bidboland II Gas Treating Plant".

For the case study, the experience on both main office and construction site of the project are analyzed and the specific risks associated with that particular industry is studied in depth to evolve a solution.

\section{Case Study: Data Analysis and Discussion}

Project name: Bidboland II Gas Treating Plant

Client: National Iranian Gas Company

Location: Behbahan, South West of Iran

Contract price: 3.3 Billion USD

Duration of work: 43 months
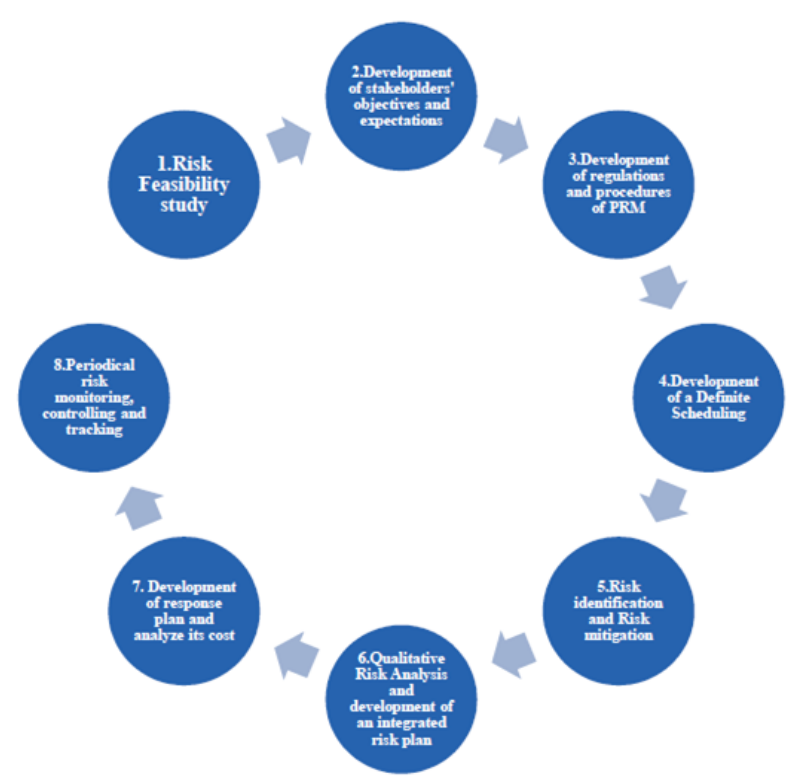

Figure 1. Risk Management Model for EPC Projects 
The specific risks associated with the Bidboland Gas Treating Plan have been studied and it was identified that the risk are spread between the Oil, Gas and the Petrochemical Industries. The following framework was constructed with existing literature work

Step 1: A Risk Feasibility Study was conducted. The major activities that were involved in this study were that of analyzing the risk management strategic planning, project life cycle study and the project implementation method. The contractor and consultants involved are also analyzed. A risk feasibility package is the main outcome at this step.

Step 2: Stakeholders objectives have to be developed by working with them. Their specifications have to be identified and based on the same; the risk feasibility analysis is conducted. The output of this stage is a risk management package that will be considerate of the stakeholder's requirements.

Step 3: The regulations and the procedures necessary for developing risk management for the EPC is identified. The main inputs to this stage are that of the risks feasibility package, the stakeholder's requirements as collected from step 2, using which the objectives of the bidboland Gas Treating Plant will be determined. The technical tools that will be used, the software packages to be used and more are determined. The risk breakdown structure is considered in this stage also. The output of this stage is the risk management manual. This manual is more custom made to the project at hand.

Step 4: From considering more top level planning, the more specific planning begins at step 4 . Here the planning output a definite plan. The main inputs that are considered at this step are that of the time schedule, the outputs of the previous steps, the risk management entities identified and documented till this step and more.

Step 5: This is the risk identification and mitigation stage. At this point, the risk management has moved on to include the plan for the different risks types. Here the input to the step are the work breakdown structure WBS and the Risk Breakdown structure RBS, risk management procedures, the manual prepared from the previous step and the specific time schedule that has been identified from the WBS. The risks that has been identified from the previous state has been refined at this stage. By refinement the meaning here is that the risks are itemized and sub itemized and have been prioritized based on their different levels of impact. Furthermore at this step, the secondary level risks are also included.

Step 6: This s a critical step at this level, a qualitative risk analysis is conducted. The integrated risk plan is developed and this risk plan is applied on the project. Here accosts and time analysis will also be concluded so as to make the risk management plan more real time. The project schedule will be the output at this stage. The project schedule will not reflect the applied risks in the previous steps; here the project schedule has been updated to reflect the applied risks. The main inputs that are used in this step are the outputs of the previous steps which includes the risk management manual, the itemized risks register, the sub procedures, the WBS and RBS applied and more. The risk response plan is developed here and is one of the key output of this stage. A risk response plan makes it easy to analyze and estimate the risk impact before and after (if the risk cannot be mitigated). Also the definitive plan will be applied here, so the key responses can be recorded for. In addition one another significance of having this as a separate step is that all the involved stakeholders and the ownership of the different project entities assigned to them, and the risk response corroborated to the specific entities are mapped. These outputs are then passed onto the risk monitoring system that will work parallel to the entire project unit.

Step 8: Periodical risk monitoring, controlling and tracking is the main emphasis on step 8. Here it is noted that the main inputs of the risk plan are identified. The risk response is taken as the input and the different owners of the plan are also identified as inputs to this subsystem. The risk response plan is executed along with the necessary units for periodical updates. The updates risk response plans for the project are the output at this stage. The benefits of using such a system in the oil and gas industry is that risk responses are constructed real time as well as planned for.

The specific risks such as Economic sanctions, Nonpayment and violation of Contracts, Gap between consumers and producers, technical Complexity and high technology used are addressed. The core area of funding by the developed nations in SEED projects as the Oil gas Project requires huge Investment and the role of Insurance players is analyzed in depth.

Table 1. List of Contractors connected with the EPC Project

\begin{tabular}{llll}
\hline Company & Related Experience Rate & Main Expertise & Participation rate \\
\hline Sarah (Iran) & Over 30 years Engineering, Procurement & Engineering, Procurement & High \\
Jahan Pars(Iran) & Over 30 years Engineering, Procurement & Construction, Procurement & High \\
SNC Lavalin (Canada) & Over 50 years & Engineering & Moderate \\
RIPI (Iran & About 20 Years & Engineering & Low \\
Prosernat (Malaysia) & About 30 years & Engineering & Low \\
\hline
\end{tabular}

The lists of contractors that are associated with the EPC project are presented above. These are the primary stakeholders associated with the project. A feasibility study will help in presenting the key risks, and the risks can then be linked back to help the stakeholders take up ownership of the risks. 
Table 2. Feasibility Study: Need for Risk Management in EPC Project

\begin{tabular}{llll}
\hline Item Description & Weight of Item & Need to Risk Management & Score \\
\hline Project risk Management Strategic Planning & 0.16 & 9 & 1.44 \\
Project Life Cycle Statutes & 0.14 & 10 & 1.4 \\
Project Overall Structure & 0.06 & 5 & 0.3 \\
Project Implementation Method & 0.16 & 9 & 1.44 \\
Project Contract and Payment Method & 0.18 & 10 & 1.8 \\
Contractors and Consultants & 0.14 & 4 & 0.56 \\
Project at the Portfolio Level of organization, ministry, country, region & 0.1 & 3 & 0.3 \\
Desired level of risk management & 0.06 & 7 & 0.42 \\
& 1 & & 7.66 \\
1-10, Number 10 means Strong need for Risk Management and 1 means low need & & \\
\hline
\end{tabular}

In general the overall risks identified can be listed as to accurate understanding of Bid documents, not undertaking a clear process to enter in the fray, not to anticipate the costs involved in getting the requisite licenses [4], not to select a proper legal person to understand the terminology used in the bidding document, and to quote a higher bid price which is not realistic in the primary area, and in the secondary area, non completion of projects on time, delay in completion of the project, not to sign an cost increase pact, non proper supervision of the Construction work and others. Each of these risk issues in EPC can be connected across to the different stakeholders which in this case are the contractors.

\section{Conclusion}

The area of project Risk Management is the new emerging field of comprehensive study, as the Mega Projects coming up currently are of highly technical and complex in detail. But there are instances where in the Oil and Gas companies are hesitant in investing on Risk Management Services [1]. They try to tackle the issues as any common problem faced in the manufacturing sector without realizing the real depth of the problem. Yet another problem is that, the project Managers are trying to empower themselves with various tools to prevent the risks, and to identify beforehand the problems which would pose a problem in the project not getting commissioned on time without a specific tool to tackle the problem. Hence, nowadays, the Engineering, Procurement and Construction companies start their risk management schedule right from the day one from floating of the tenders to the bidding of the tenders, and in finalization of the work contracts and so on. Even if the Risk management protocol is observed, the grey area has lack of continuous monitoring and identification, control, and insufficient risk response plan. Such is the situation prevalent in this industry, and as the case study highlights a continuous and constant watch upon its own actions is needed. This means keeping abreast of the new technologies and inputs towards track risk based problems and finding a logical and correct solution.

Adding to the above problems, the risk management procedures that are made use of in the sector are often very generic. They are projected for use for many things and have to be tailored down to meet the demands of a specific industry. This research has pointed out how a customized methodology can be made possible. Through this methodology it will be possible to identify the top level risks at the time of project procurement itself, so the planning of the project can be done around it. It is the top level abstraction of risks that when are not mitigated results in heavy loss in the form of time and money. This situation further gets exacerbated by element such as the project location critical parameters, the environment, the macro-environmental factors and more. Identification and evaluation of risks earlier on will help create mitigation strategies that focus on the risk. Even if the actual risk cannot be averted, the risk will be managed or minimized. Adverse consequences are reduced. Only with a defined risk management model this is possible.

The research specifically presents a risk management model that is applicable for risk analysis in the EPC projects of the oil and gas industry. The risk management framework that is presented is more detailed and internetworked with software technologies and techniques that most other generic models do not present. Some of the techniques that are being used here are the PERT, GERT and/or Mont Carlo. Higher performance and productivity is possible with these techniques. The technical requirements and other aspects of the model were developed keeping in mind the research literature available on risk management in the oil and gas industry. It is noted that there is a general combination of the PMBOK, PRINCE2 and Cooper that has been used in the Gas industry. Each of these techniques comes with its own set of advantages and disadvantages, and care has to be taken to ensure that the application is well thought of. Also most of the models in risk management start off with the risk identification procedure and the management, while this does have its strength, the construction company's entire process structure does not come into analysis. This research has suggested for a risk feasibility study. This is a very comprehensive study. The risk feasibility analysis will be conducted with the a comprehensive overview of the company processes, such as its strategic plans, the entire life cycle for the oil and gas constructions, the implementation, procurement processes and details, payment, client portfolio, contractor level profiles, and more. This form of a comprehensive arrangement that is done for risk study even before the actual project is set up actually offers many advantages. Primarily it can be seen companies might base their decisions to attend the tender meetings based on the foreseen risks. Companies are better advised on how they 
could handle the risks and how this would affect the tender contracting. There are much legal entities involved once the contract is signed off, and a risk management analysis done after the procurement most often would mean that the constructor is constrained for options to deal with the risks. There will be geo-political issues and additional legislative factors that might constrain them from having adequate support. When a proper feasibility study is submitted before hand, then the companies have better competitive advantage [8] In order to complete a project successfully it is necessary that there is a periodical risk monitoring available. Risk registers have to be developed and additional resources be deployed to handle the identified risks. These and more issue can be negotiated at the tendering time when the research recommendation is followed.

The research work is not a final recommendation however, it is more of groundwork on how the EPC projects will be able to better make use of risk management when tendering, accepting and implementing projects. Bidboland II gas treating plant project is where the methodology has been tested out. It is seen that functional risks are averted better and there is also better documentation procedure in risk handling that will be useful for future commissioning. Furthermore the risk management is spread across, from the pre-tendering stage to the post-commissioning stage. This risk management recommendation hence will be useful for the oil and gas industry to further develop custom methodologies according to their company policies and can also be employed by Government entities when they subcontract out their projects to private contractors, as they will be able to pack much transparency of risks involved when subcontracting.

\section{References}

[1] Burke, R., 1999. Project Management: Planning \& Control Techniques. 3rd ed. New York: John Wiley and Sons.
[2] Fairley, R., 1994. Risk Management for Software Projects. IEEE Software. 11(3), pp. 57-67.

[3] Haghnevis, M. and Sajedi, H., 2006. A model for assessment of project management risk models. 4th International Management Conference. Tehran, Iran, 19-20 [online] Available

http://mba.mbairan.ir/Portals/0/388_Full_moeed.pdf, [Accessed on March 18, 2015]

[4] Heldman, K., 2005, Project manager's spotlight on risk management. San Francisco: Harbor Light Press.

[5] Huse, A. J., 2002. Understanding and negotiating turnkey and EPC contracts. 2nd ed. London: Sweet \& Maxwell Ltd.

[6] Kangari, R., 1995. Risk management perceptions and trends of US construction. Journal of Construction Engineering and Management. 121(4), pp. 422-429.

[7] Loots, P. and Henchie, N., 2007, Worlds Apart: EPC and EPCM Contracts: Risk issues and allocation. International Construction Law Review. 24(1), pp. 252-270.

[8] March, J.G. and Shapira, Z., 1987. Managerial perspectives on risk and risk taking. Management Science. 33(11), pp. 1404-1418.

[9] Mulcahy, R., 2003. Risk Management: Tricks of the Trade for Project Managers. Minnesota: RMC Publications.

[10] Project Management Institute, 2008. ANSI/PMI 99-001-2008, A Guide to the Project Management Body of Knowledge. Newtown Square, Pennsylvania: PMI (Project Management Institute).

[11] Ramasamy, S., 2005. Total Quality Management, Delhi: Tata McGraw-Hill. 